\title{
Paraoxonase (PON)- I: a brief overview on genetics, structure, polymorphisms and clinical relevance
}

This article was published in the following Dove Press journal: Vascular Health and Risk Management

\author{
Nelusha Shunmoogam' \\ Poobalan Naidoo' \\ Robert Chilton ${ }^{2}$ \\ 'Sanofi, Midrand, South Africa; \\ 2Department of Medicine, Division \\ of Cardiology and Interventional \\ Cardiology, University of Texas Health \\ Science Center at San Antonia, San \\ Antonia, TX, USA
}

\begin{abstract}
Paraoxonase-1 (PON1) is a high-density lipoprotein-associated esterase and is speculated to play a role in several human diseases including diabetes mellitus and atherosclerosis. Low PON1 activity has been associated with increased risk of major cardiovascular events, therefore a variety of studies have been conducted to establish the cardioprotective properties and clinical relevance of PON1. The major aim of this review was to highlight the important studies and to subsequently assess if PON1 has clinical relevance. A review of the literature showed that there is currently insufficient data to suggest that PON1 has clinical relevance. It is our opinion that robust studies are required to clarify the clinical relevance of PON1.
\end{abstract}

Keywords: antioxidant, inflammation, atherosclerosis, cardiovascular disease

\section{Introduction}

Human serum paraoxonase-1 (PON1) is a calcium-dependent hydrolytic enzyme that is found in a variety of mammalian species. Abraham Mazur ${ }^{1}$ and Norman Aldridge ${ }^{2}$ played a pivotal role in the identification and classification of PON1 in the mid-1940s to early 1950 s. Initially, the enzymes were referred to as “A”-esterases, but later became universally known as paraoxonases due to their ability to detoxify the organophosphate compound paraoxon which is the toxic metabolite of parathion, a commonly used agricultural insecticide. ${ }^{3}$

PON1 belongs to a family of three serum paraoxonases, including PON2 and PON3; however, PON1 remains the most popular member of this family. ${ }^{4}$ This is largely due to the elegant studies by Mackness et al that described the role of high-density lipoprotein (HDL)-associated PON1 in decreasing lipid peroxide accumulation on low-density lipoprotein (LDL).$^{5-7}$ This highlighted a link to PON1 and cardiovascular disease, which sparked the research interest in PON1, mainly to elucidate the precise physiological mechanisms of the enzyme. In addition, PON1 hydrolyzes homocysteine thiolactone. Homocysteine thiolactonase activity of PON1 protects against $N$-homocysteinylation, which is detrimental to protein structure and function. ${ }^{8}$

\section{Structure of PONI}

PON1 is a calcium-dependent enzyme consisting of 354 amino acids with a molecular mass of $43 \mathrm{kDa}$. Structural analysis using X-ray crystallography revealed the sixbladed $\beta$-propeller structure of PON1 (Figure 1), with a central tunnel that houses two calcium ions. ${ }^{9}$ Each calcium ion, depending on its location within the enzyme, plays an important part in the activity of PON1. ${ }^{10}$ The calcium ion located deeper within
Correspondence: Nelusha Shunmoogam Sanofi, Sanofi House, 2 Bond Street, Grand Central, Midrand, I685, South Africa

Tel +27 I I 2563700

Fax +27 II 8475099

Email nelushal@gmail.com 


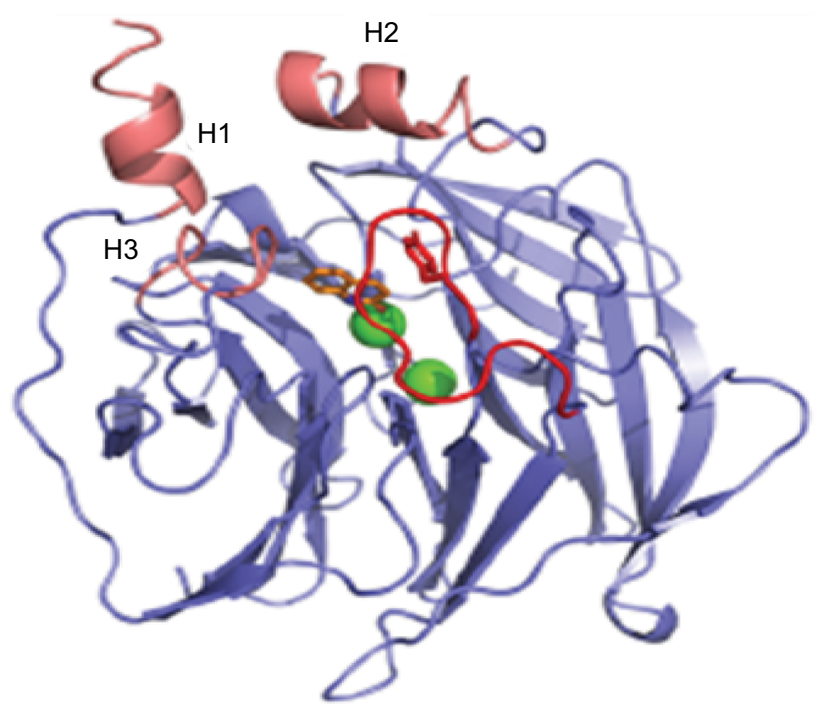

Figure I Structure of recombinant PONI illustrating the position of the $\mathrm{Ca}^{2+}$ ions (green) and the three helices (pink).

Note: $\mathrm{HI}=$ Helix $\mathrm{I}, \mathrm{H} 2=$ Helix 2 and $\mathrm{H} 3=$ Helix 3. Reproduced from Blaha-Nelson $D$, Krüger DM, Szeler K, et al. Active site hydrophobicity and the convergent evolution of paraoxonase activity in structurally divergent enzymes: the case of serum paraoxonase I. J Am Chem Soc. 2017;139(3): I I55-1167.?

Abbreviation: PONI, Paraoxonase-I.

the tunnel has a structural role that is critical for the conformational stability of PON1. The other calcium ion which lies at the bottom of the active site cavity has a catalytic role and is important for substrate positioning and ester bond activation. Three helices are located above the active site of PON1: $\mathrm{H} 1, \mathrm{H} 2$ and $\mathrm{H} 3$, where $\mathrm{H} 1$ and $\mathrm{H} 2$ have functions in PON1-HDL interactions. ${ }^{9}$

\section{Genetics of PON I}

The human PON1 gene is a member of a multigene family consisting of three members in total. PON1, PON2 and $P O N 3$ are located next to each other on chromosome 7 and share extensive structural homology. Interestingly, $P O N 1$ can be differentiated from $P O N 2$ and $P O N 3$ by the three extra nucleotide residues in exon $4 .{ }^{11}$ The genes for this family are expressed in various mammalian tissues, with PON1 and PON3 primarily synthesized in the liver and mostly found associated with HDL in the plasma. ${ }^{12,13}$ PON1 forms part of a repertoire of HDL-associated enzymes, including lecithin-cholesterol acyltransferase and platelet-activating factor acetyl-hydrolase, responsible for the antioxidative activity of HDL.

\section{PONI polymorphisms}

Human PON1 has many single-nucleotide polymorphisms (SNPs); eight have been identified on the promoter region and 176 within the gene sequence, ${ }^{14}$ some of which exert changes in PON1 level and activity. These polymorphisms may also affect the risk for disease development and the severity of disease. ${ }^{15}$ Studies have identified two common polymorphisms in the coding region (at positions 55 and 192) that have been reported to affect the activity and concentration of PON1. ${ }^{16}$ The leucine/methionine polymorphism at position 55 of the amino acid sequence (L55M) has been associated with changes in PON1 serum concentrations, and an association with the occurrence of cardiovascular disease was also observed. ${ }^{17}$ The glutamine/arginine polymorphism at position 192 (Q192R) has been shown to affect PON1 activity, where the Q192 isoform was demonstrated to hydrolyze paraoxon and metabolize oxidized LDL more effectively than the R192 isoform. ${ }^{18}$ The Q192R polymorphism is regarded as the chief biomarker of oxidant status, where LDL oxidation is prevented the most in QQ homozygous patients and the least in RR patients. ${ }^{19}$

In addition, three common SNPs (G-907C, A-162G and $\mathrm{C}-108 \mathrm{~T}$ ) were identified in the promoter sequence of the PON1 gene. ${ }^{14}$ These polymorphisms are associated with considerable differences in PON1 concentration and activity, and they have also been implicated in the presence of coronary heart disease. ${ }^{20}$ It has been well established that low PON1 activity is linked with an increased risk of cardiovascular disease, implicating PON1 as a physiologically important enzyme.

\section{Clinical relevance}

PON1 is an HDL-associated protein that has the ability to hydrolyze oxidized LDL-cholesterol, with potential atheroprotective effects. ${ }^{21}$ Furthermore, PON1 can cleave phospholipid peroxidation adducts with potential cytoprotective functions. ${ }^{22}$ Given these potential atheroprotective effects, and the large burden of atherosclerotic cardiovascular disease, considerable work has focused on elucidating the clinical relevance of PON1.

Animal studies ${ }^{23,24}$ have suggested atheroprotective benefits of PON1. Transgenic mice overproducing human PON1 protected them from atherosclerosis, when compared to wild-type mice. ${ }^{23}$ In addition, PON1-deficient mice are at greater risk of developing atherosclerosis than wild-type mice. ${ }^{24}$ Animal studies have various limitations and direct extrapolation to humans cannot be made. However, they are useful for "transiting" from in vitro studies to clinical studies.

With respect to clinical studies, Mackness et $\mathrm{al}^{20}$ investigated the effects of the C-108T and G-909C promoter polymorphisms on PON1 levels and the presence of coronary heart disease (CHD). It was a case-control study, with 417 people with CHD and 282 healthy controls. PON1 activity and concentration were significantly lower in the 
CHD population compared to controls, regardless of their C-108T and G-909C genotype $(p<0.001)$. Both promoter polymorphisms were not associated with $\mathrm{CHD}$ presence and the authors concluded that PON1 status was significantly lower in people with CHD.

Azarsiz et $\mathrm{al}^{25}$ investigated PON1 activity in patients with angiographically confirmed CHD. Twenty-four healthy volunteers and 101 patients were enrolled in the study; 68 patients had coronary artery disease, which was confirmed by coronary angiography. PON1 activities of patients with CHD were lower than those of controls; however, this difference was statistically insignificant. In contrast to Azarsiz et al's study, ${ }^{25}$ Sharma et al $^{26}$ demonstrated that serum PON1 activity was significantly low in CHD patients. Sharma et al investigated PON1 activity in 200 patients suffering from CHD and 150 normal individuals. CHD patients were classified into two groups on the basis of associated risk factors (diabetes mellitus, hypertension): group 1 ( $n=120$; CHD patients with associated risk factors) and group $2(n=80$; CHD patients with no associated risk factors). ${ }^{26}$

Smoking is an important independent risk factor for CHD, and a study by Han et $\mathrm{al}^{27}$ showed that cigarette smoking status together with the presence of common PON1 SNPs play a role in the risk of developing $\mathrm{CHD}^{27}$ In this casecontrol study nested within the Singapore Chinese Health Study, which was a prospective cohort of 63,257 participants recruited over 5 years, Han et al evaluated 1,914 Singaporean Chinese: 688 cases and 1,226 controls. The participants were stratified according to cigarette smoking status as ever-smokers ( $n=813)$, who answered yes to smoking at least one cigarette a day for a year or longer, and never-smokers $(\mathrm{n}=1,101)$. The T allele of the PON1 rs662 polymorphism was shown to be associated with an increased risk of CHD among ever-smokers only (odds ratio $[\mathrm{OR}]=1.35,95 \%$ CI 1.08-1.68; adjusted $p=0.036$ ), whereas another PON1 SNP, rs3735590, was shown to be associated with an increase in CHD among never-smokers only $(\mathrm{OR}=1.53,95 \%$ CI $1.11-2.11$; adjusted $p=0.036),{ }^{27}$ highlighting that more research is required on PON1 polymorphisms and CHD.

Kunutsor et $\mathrm{al}^{28}$ investigated the association of PON1 with cardiovascular risk. The study included prospectively measuring PON1 activity in 6,902 study subjects. The study subjects were followed up for a mean of 9.3 years, with 730 adverse cardiovascular events being recorded. There is an approximately log-linear inverse association between PON1 activity and CVD risk, which is partly dependent on HDL-cholesterol levels. Kunutsor et al did a further meta-analysis of six stud- ies with 15,064 study subjects and 2,958 incident adverse cardiovascular events. Based on the findings of Kunutsor et al, although there is a negative relationship between PON1 and adverse cardiovascular events, PON1 does not add value to cardiovascular risk stratification, beyond conventional cardiovascular risk factors. $^{28}$

Given that atherosclerotic cardiovascular disease is a major cause of mortality, it was hypothesized that older individuals may have lower PON1 activity, when compared to younger individuals. Seres et $\mathrm{al}^{29}$ investigated the relationship between age and serum PON1 activity. One hundred twentynine healthy subjects aged between 22 and 89 years were included in their study. Serum PON1 activity significantly decreased with age $(r=-0.38, p<0.0001)$. HDL concentrations remained unchanged with age; however, Apo A1 concentration showed a slight negative, but significant correlation with age ( $r=-0.19, p<0.027)$. Moreover, the total cholesterol concentration was positively and significantly correlated with age $(r=0.40, p<0.001)$. The authors also noted that HDL from elderly subjects was more susceptible to oxidation than HDL from young subjects, measured by higher lipid peroxidation rate. The study was limited by relatively small sample size, but did demonstrate reduction in PON1 activity with age.

Numerous further studies investigated whether PON1 is a longevity gene. Lescai et $\mathrm{al}^{30}$ carried out a meta-analysis of these aforementioned studies that included 5,962 subjects: 2,795 young controls ( $<65$ years of age) and 3,167 old subjects ( $>65$ years of age). R carriers demonstrated a significant result with an overall OR of 1.16 (95\% CI 1.04-1.30, $p=0.006)$. The QR genotype also showed a significant result, with an overall OR of 1.14 (95\% CI 1.02-1.27, $p=0.016)$. The authors concluded that PON1 gene variants at codon 192 impact on the probability of attaining longevity, and those subjects carrying $\mathrm{RR}$ and $\mathrm{QR}$ genotypes ( $\mathrm{R}+$ carriers) are favored in reaching extreme ages. However, subsequent meta-analysis with larger number of patients ${ }^{31,32}$ has suggested that there is no effect of PON1 on human longevity. However, population-specific effects could not be excluded. The aforementioned metaanalysis may be limited by publication bias and variations in analytical procedures used to measure PON1 activity.

Another meta-analysis based on 30 publications analyzed the risk of cancer in relation to the PON1 Q192R polymorphism. ${ }^{33}$ Considering PON1 polymorphisms have been associated with several types of cancer, Zhang et al investigated the role of the genetic variant Q192R in cancer susceptibility. The authors conducted a thorough search of the literature and based on robust inclusion criteria, their meta-analysis exam- 
ined 30 publications with a total of 8,112 cases and 10,037 controls. The results indicated that the PON1-192 R allele was associated with a reduced risk of overall cancers compared to the $192 \mathrm{Q}$ allele (OR=0.842, 95\% CI 0.725-0.979); however, when the results were analyzed according to the cancer types, an increased and decreased risk of cancer subtypes were observed under heterozygous, homozygous, dominant and recessive models. ${ }^{33}$ It is well established that oxidative stress and increased free radicals may lead to an increased risk of cancer; therefore, the antioxidant properties of the genetic variants of PON1 should be studied in more detail to fully understand their role in cancer.

Diabetes mellitus is characterized by increased oxidative stress and damage, possibly due to the result of glycosylation of LDL by glucose. ${ }^{34}$ Various studies ${ }^{35-39}$ have demonstrated a reduction in PON1 in type 2 diabetic patients. Furthermore, reduced PON1 activity in type 2 diabetes mellitus has been associated with increased risk of cardiovascular disease. ${ }^{40}$ Rozek et al postulated that reduced PON1 activity in diabetic patients results in reduced HDL protective activity against cell membrane peroxidation contributing to increased arteriosclerosis in diabetic patients. ${ }^{41}$ Studies demonstrating reduction in PON1 levels in diabetic patients are contradicted by studies that show no changes in the levels of PON1 in diabetic subjects. ${ }^{42-44}$ However, although the aforementioned studies showed no absolute reductions in PON1 levels, they demonstrated qualitative reductions in PON1 activity.

Nie et al conducted a meta-analysis on the relationship of PON genes and Alzheimer's disease. ${ }^{45}$ Fifteen studies (involving five polymorphisms) were included in the metaanalysis. The authors concluded that the "SS genotype of PON2 S311C polymorphism had a significant association with Alzheimer's disease in the studied population, and the A allele of PON1 rs705379 polymorphism was positively related to $\mathrm{AD}$ in the Caucasian population as well as the GG genotype decreased AD risk significantly in Caucasians." 45 The meta-analysis is limited by the quality of studies included; further robust studies are required to elucidate the role of PON in Alzheimer's disease.

Liu et al conducted a systematic review and meta-analysis of PON gene polymorphisms and ischemic stroke. ${ }^{46}$ Twentyeight studies were included in the meta-analysis. The $\mathrm{R}$ allele or RR genotype of PON1 Q192R polymorphism had an increased risk for ischemic stroke in the general population, but there was no significant association between other genetic variants of $P O N$ gene and ischemic stroke. ${ }^{46}$ Again, the quality of the studies included in the meta-analysis and systematic review lack robustness, and thus, global inferences cannot be made from this study.

Organophosphates are chemicals commonly used in insecticides. They are also sometimes ingested by humans either accidently or intentionally to commit suicide. PON1 has shown activity against organophosphates, and individuals with higher levels of PON1 may be protected against the harmful effects of organophosphates. ${ }^{47}$ However, PON1 levels are not employed routinely during the management of organophosphate poisoning, and probably will not be included in future management algorithms because they are unlikely to affect treatment.

Figure 2 illustrates the potential clinical role of PON, and Table 1 lists the key teaching points.

\section{Pharmacological interactions of PON I}

A detailed review of the relationship between PON1 and pharmacological agents is beyond the scope of this review. A comprehensive review by $\mathrm{Mahrooz}^{48}$ describes the interactions of PON1 with cardiovascular drugs, antidiabetic drugs, antibiotics, anticancer drugs, antidepressants and contraceptives. There remains a large amount of incongruences in the study findings, and the clinical relevance of PON1 remains to be further investigated. Mahrooz attributes "dosage and type of drug, length of treatment, genetic variations, particularly loss-of-function polymorphisms, and the model used (cultured cells, animal studies, or human studies)" for the variability of study results. ${ }^{48}$

As an example, we will describe the studies of PON1 and the antiplatelet drug, clopidogrel. Bouman et $\mathrm{al}^{49}$ investigated the clinical relevance of the PON1 Q192R genotype in a population of individuals with coronary artery disease who underwent stent implantation and received clopidogrel therapy. PON1 QQ192 homozygous individuals showed a considerably higher risk than RR192 homozygous individuals of stent thrombosis, lower PON1 plasma activity, lower plasma concentrations of active metabolite and lower platelet inhibition. ${ }^{49}$ The findings of Bouman et al were contradicted by a systematic review and meta-analysis. ${ }^{50,51}$ Given the aforementioned incongruent study findings, PON1 levels are currently not measured routinely during treatment with clopidogrel and are not included in mainstream clinical guidelines. 
Clinical consideration
of paraoxonase

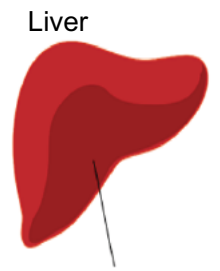

Secreted into circulation Expressed on most tissues

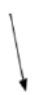

HDL associated PON1 and 3
Insulin resistance?

Increased wall stress?

Biomarker?

Cellular/mitochondrial stress?

Stabilizes vulnerable plaques $\uparrow \uparrow$ Cholesterol efflux from macrophages

Clinically potent antioxidant

Hydrolysis of lipid peroxides and hydrogen peroxides

Inhibits oxidation of lipids

PON2 is expressed on most tissues, but does not circulate

Figure 2 The liver secretes HDL-associated PON into the systemic circulation. PON has antioxidant properties, stabilizes vulnerable atherosclerotic plaques and limits plaque rupture, with the potential limitation of atherosclerotic cardiovascular disease. PON has the potential to serve as a biomarker for cellular stress, vascular wall stress and insulin resistance.

Abbreviations: HDL, high-density lipoprotein; PON, paraoxonase.

Table I Key teaching points

PONI is an HDL-associated calcium-dependent enzyme involved in decreasing oxidized LDL-cholesterol

$P O N I$ is a member of a multigene family and is primarily synthesized in the liver

The PONI gene has single-nucleotide polymorphisms which influence the enzyme level and activity

A variety of studies have been performed to investigate the clinical relevance of PONI in a number of diseases including cardiovascular disease,

diabetes, neurologic diseases and cancer

Preclinical and clinical data are currently insufficient and, in some cases, contradictory

Further robust studies are required to elucidate the precise role of PONI in human diseases

Abbreviations: HDL, high-density lipoprotein; LDL, low-density lipoprotein; PONI, paraoxonase-I.

\section{Conclusion}

Although the preclinical and clinical studies around PON1 are intriguing, there is currently insufficient data to suggest that PON1 has clinical relevance. Furthermore, the study findings are incongruent and, in some instances, contradictory. Robust studies are required to clarify the clinical relevance of PON1.

\section{Disclosure}

PN is employed by Sanofi and NS is a previous employee of Sanofi. Sanofi has molecules in the lipid, antiplatelet, hypertension, diabetes, anticancer, anti-infective and antidepressant therapeutic areas. Neither PN nor NS own stocks in Sanofi. The other author reports no conflicts of interest in this work.

\section{References}

1. Mazur A. An enzyme in animal tissues capable of hydrolysing the phosphorus-fluorine bond of alkyl fluorophosphates. $J$ Biol Chem. 1946;164:271-289.

2. Aldridge WN. Serum esterases 2- An enzyme hydrolysing diethyl p-nitrophenylphosphate (E600) and its identity with the A-esterase of mammalian sera. Biochem. J. 1953;53:117-124.

3. Mackness M, Mackness B. Human Paraoxonase-1 (PON1): gene structure and expression, promiscuous activities and multiple physiological roles. Gene. 2015;567(1):12-21.

4. Précourt LP, Amre D, Denis MC, et al. The three-gene paraoxonase family: physiologic roles, actions and regulation. Atherosclerosis. 2011;214(1):20-36. 
5. Mackness MI, Arrol S, Durrington PN. Paraoxonase prevents accumulation of lipoperoxides in low-density lipoprotein. FEBS Lett. 1991;286:152-154.

6. Mackness MI, Abbott CA, Arrol S, Durrington PN. The role of highdensity lipoprotein and lipid-soluble antioxidant vitamins in inhibiting low-density lipoprotein oxidation. Biochem. J. 1993a;294:829-834.

7. Mackness MI, Arrol S, Abbott CA, et al. Protection of low-density lipoprotein against oxidative modification by high-density lipoprotein associated paraoxonase. Atherosclerosis. 1993;104:129-135.

8. Perła-Kaján J, Jakubowski H. Paraoxonase 1 and homocysteine metabolism. Amino Acids. 2012;43(4):1405-1417.

9. Blaha-Nelson D, Krüger DM, Szeler K, et al. Active site hydrophobicity and the convergent evolution of paraoxonase activity in structurally divergent enzymes: the case of serum paraoxonase 1. J Am Chem Soc. 2017;139(3):1155-1167.

10. Vitarius JA, Sultatos LG. The role of calcium in the hydrolysis of the organophosphate paraoxon by human serum A-esterase. Life Sci. 1995;56(2):125-134.

11. Primo-Parma SL, Sorenson RC, Teiber J, La Du BN. The human serum araoxonase/arylesterase gene (PON1) is one member of a multigene family. Genomics. 1996;33:498-509.

12. Rodríguez-Sanabria F, Rull A, Beltrán-Debón R, et al. Tissue distribution and expression of paraoxonases and chemokines in mouse: the ubiquitous and joint localisation suggest a systemic and coordinated role. J Mol Histol. 2010;41(6):379-386.

13. Aviram M, Rosenblat M. Paraoxonases 1, 2, and 3, oxidative stress, and macrophage foam cell formation during atherosclerosis development. Free Radic Biol Med. 2004;37(9):1304-1316.

14. Najafi M, Gohari LH, Firoozrai M. Paraoxonase 1 gene promoter polymorphisms are associated with the extent of stenosis in coronary arteries. Thromb Res. 2009;123(3):503-510.

15. Ponce-Ruiz N, Murillo-González FE, Rojas-García AE, et al. Transcriptional regulation of human Paraoxonase 1 by nuclear receptors. Chem Biol Interact. 2017;268:77-84.

16. Humbert R, Adler DA, Disteche CM, et al. The molecular basis of the human serum paraoxonase activity polymorphism. Nat Genet. 1993;3(1):73-76.

17. Blatter Garin MC, James RW, Dussoix P, et al. Paraoxonase polymorphism Met-Leu54 is associated with modified serum concentrations of the enzyme. A possible link between the paraoxonase gene and increased risk of cardiovascular disease in diabetes. J Clin Invest. 1997;99(1):62-66

18. Costa LG, Cole TB, Vitalone A, Furlong CE. Measurement of paraoxonase (PON1) status as a potential biomarker of susceptibility to organophosphate toxicity. Clin Chim Acta. 2005;352(1-2):37-47.

19. Dounousi E, Bouba I, Spoto B, et al. A genetic biomarker of oxidative stress, the Paraoxonase-1 Q192R gene variant, associates with cardiomyopathy in CKD: a longitudinal study. Oxid Med Cell Longev. 2016;2016:1507270.

20. Mackness B, Turkie W, Mackness M. Paraoxonase-1 (PON1) promoter region polymorphisms, serum PON1 status and coronary heartdisease. Arch Med Sci. 2013;9(1):8-13.

21. Getz GS, Reardon CA. Paraoxonase, a cardioprotective enzyme: continuing issues. Curr Opin Lipidol. 2004;15(3):261-267.

22. Chistiakov DA, Melnichenko AA, Orekhov AN, Bobryshev YV. Paraoxonase and atherosclerosis-related cardiovascular diseases. Biochimie. 2017;132:19-27.

23. Tward A, Xia YR, Wang XP, et al. Decreased atherosclerotic lesion formation in human serum paraoxonase transgenic mice. Circulation. 2002;106(4):484-490

24. Shih DM, Gu L, Xia YR, et al. Mice lacking serum paraoxonase are susceptible to organophosphate toxicity and atherosclerosis. Nature. 1998;(394):284-287.

25. Azarsiz E, Kayikcioglu M, Payzin S, Yildirim Sözmen E. PON1 activities and oxidative markers of LDL in patients with angiographically proven coronary artery disease. Int J Cardiol. 2003;91(1):43-51.

26. Sharma R, Singh B, Mahajan M. PON1 activity is inversely related to LDL apoB carbonyl content in patients with coronary artery disease. Kaohsiung J Med Sci. 2007;23(5):225-231.
27. Han Y, Dorajoo R, Ke T, et al. Interaction effects between Paraoxonase 1 variants and cigarette smoking on risk of coronary heart disease in a Singaporean Chinese population. Atherosclerosis. 2015;240(1):40-45.

28. Kunutsor SK, Bakker SJ, James RW, Dullaart RP. Serum paraoxonase-1 activity and risk of incident cardiovascular disease: the PREVEND study and meta-analysis of prospective population studies. Atherosclerosis. 2016;245:143-154.

29. Seres I, Paragh G, Deschene E, Fulop T Jr, Khalil A. Study of factors influencing the decreased HDL associated PON1 activity with aging. Exp Gerontol. 2004;39(1):59-66.

30. Lescai F, Marchegiani F, Franceschi C. PON1 is a longevity gene: results of a meta-analysis. Ageing Res Rev. 2009;8(4):277-284.

31. Caliebe A, Kleindorp R, Blanché H, et al. No or only population-specific effect of PON1 on human longevity: a comprehensive meta-analysis. Ageing Res Rev. 2010;9(3):238-244.

32. Wei GZ, Zhu MY, Wang F, et al. Paraoxonase (PON1) polymorphisms Q192R and L55M are not associated with human longevity: a metaanalysis. Z Gerontol Geriatr. 2016;49(1):24-31.

33. Zhang M, Xiong H, Fang L, et al. Paraoxonase 1 (PON1) Q192R gene polymorphism and cancer risk: a meta-analysis based on 30 publications. Asian Pac J Cancer Prev. 2015;16(10):4457-4463.

34. Baynes JW, Role of oxidative stress in development of complications in diabetes. Diabetes. 1991;40:405-412.

35. Gupta N, Binukumar BK, Singh S, et al. Serum paraoxonase-1 (PON1) activities (PONase/AREase) and polymorphisms in patients with type 2 diabetes mellitus in a North-West Indian population. Gene. 2011;487:88-95.

36. Hedrick CC, Thorpe SR, Fu M-X, et al. Glycation impairs high density lipoprotein function. Diabetologia. 2000;43:312-320.

37. Singh D, Venketesh S, Verma JS, Lellamma CO, Goel RC. Paraoxonase (PON1) activity in north west Indian Punjabis with coronary artery disease \& type 2 diabetes mellitus. Indian J Med Res. 2007;125: 783-787.

38. El-Saida NE, Nasr-Allaha MM, Sadika NA, Sharaf SA. Paraoxonase-1 activity in type 2 diabetes mellitus with and without nephropathy. Egypt J Intern Med. 2015;27:63-68.

39. Namitha D, Nusrath A, Rajeshwari A, Rani NA. Serum paraoxonase levels in type 2 diabetes mellitus patients: a case control study. J Med Sci Health. 2015;1(2):14-18.

40. Flekac M, Skrha J, Zidkova K, Lacinová Z, Hilgertová J. Paraoxonase 1 gene polymorphism and enzyme activities in diabetes mellitus. Physiol Res. 2008;57:717-726.

41. Rozek LS, Hatsukami TS, Richter RJ, et al. The correlation of paraoxonase (PON1) activity with lipid and lipoprotein levels differs with vascular disease status. J Lipid Res. 2005;46(9):1888-1895.

42. Jarvik GP, Hatsukami TS, Carlson C, et al. Paraoxonase activity, but not haplotype utilizing the linkage disequilibrium structure, predicts vascular disease. Arterioscler Thromb Vasc Biol. 2003;23: 1465-1471.

43. Rector RS, Warner SO, Liu Y, et al. Exercise and diet induced weight loss improves measures of oxidative stress and insulin sensitivity in adults with characteristics of the metabolic syndrome. Am J Physiol Endocrinol Metab. 2007;293:E500-E506.

44. Amuna RA, Mythili SV, Shunmugam N. Study on Paraoxonase 1 in type 2 diabetes mellitus. Indian J Physiol Pharmacol. 2014;58(1):13-16.

45. NieY, Luo D, Yang M, et al. A meta-analysis on the relationship of the PON genes and Alzheimer disease. J Geriatr Psychiatry Neurol. 2017;30(6): 303-310.

46. Liu H, Xia P, Liu M, et al. PON gene polymorphisms and ischaemic stroke: a systematic review and meta analysis. Int J Stroke. 2013;8(2):111-123.

47. Richard SA, Frank EA, D'Souza CJ. Correlation between cholinesterase and Paraoxonase 1 activities: case Series of pesticide poisoning subjects. Bioimpacts. 2013;3(3):119-122.

48. Mahrooz A. Pharmacological interactions of Paraoxonase 1 (PON1): a HDL-bound antiatherogenic enzyme. Curr Clin Pharmacol. 2016;11(4): 259-264.

49. Bouman HJ, Schömig E, van Werkum JW, et al. Paraoxonase-1 is a major determinant of clopidogrel efficacy. Nat Med. 2011;17(1):110-116. 
50. Reny JL, Combescure C, Daali Y, Fontana P; PON1 Meta-Analysis Group. PON1 Meta-Analysis Group. Influence of the paraoxonase-1 Q192R genetic variant on clopidogrel responsiveness and recurrent cardiovascular events: a systematic review and meta-analysis. JThromb Haemost. 2012;10:1242-1251.
51. Mega JL, Close SL, Wiviott SD, et al. PON1 Q192R genetic variant and response to clopidogrel and prasugrel: pharmacokinetics, pharmacodynamics, and a meta-analysis of clinical outcomes. J Thromb Thrombolysis. 2016;41:374-383.

\section{Publish your work in this journal}

Vascular Health and Risk Management is an international, peerreviewed journal of therapeutics and risk management, focusing on concise rapid reporting of clinical studies on the processes involved in the maintenance of vascular health; the monitoring, prevention and treatment of vascular disease and its sequelae; and the involvement of metabolic disorders, particularly diabetes. This journal is indexed on PubMed Central and MedLine. The manuscript management system is completely online and includes a very quick and fair peer-review system, which is all easy to use. Visit http://www.dovepress.com/ testimonials.php to read real quotes from published authors.

Submit your manuscript here: https://www.dovepress.com/vascular-health-and-risk-management-journal 